\title{
Inside the Antichamber: How Purposeful Game Design Reveals and Refines Player Archetypes
}

\author{
Katherine Carl, Governors State University, Katherine.e.carl@gmail.com \\ Jeffry Babb, West Texas A\&M University, jbabb@wtamu.edu \\ Mark Keith, Brigham Young University, mark.keith@gmail.com \\ Alexandra Spruill, Brigham Young University, alex.spruill95@gmail.com
}

\begin{abstract}
Video games are an omnipresent component of contemporary culture that have shaped and influenced players and their behaviors. While gamification is a body of theory-laden knowledge that has emerged as a byproduct of the influence and reach of video games, little theorizing has been done about games, game design, and playstyles as indicators of player perceptions and behaviors. We explore this phenomenon with a qualitative study that examines how game design may influence players' problem-solving and problem-setting, and how player problem-setting and -solving reveals their approaches as a player archetypes. Additionally, we investigate how such game design and gameplay may enhance Creative SelfEfficacy (CreaSE). Using content analysis, we examine how the game design of Antichamber models the application of reflective practice, how this design reveals players' problem-solving and problem-setting skills through gameplay, and how players' CreaSE is influenced by their experience and archetypes. We find that CreaSE is more malleable for certain player archetypes. In summary, we investigate how game design applies reflective practice, how the application of such theory influences players' behavior, and its implications for CreaSE.
\end{abstract}

Keywords: construal level theory; reflective practice; content analysis; qualitative research methods; tacit knowledge; repertoire development

\section{Introduction}

Video game research has evolved to explain how game elements can enhance individual employee productivity and other non-games outcomes (Treiblmaier et al., 2018). One outcome that is particularly interesting to the information systems (IS) domain is the effects of video gaming on creativity (Hutton and Sundar, 2010) and creative problem-solving (Payne et al., 2018). Because creative problem-solving is a crucial task in organizations (Tierney and Farmer, 2002), and if video gaming can truly inspire creative problem-solving, then understanding how this relationship takes place in practice would be quite useful to organizations. In this sense, video games - and the genre of problem-solving video gaming in particularcan be considered a form of gamification (Treiblmaier et al., 2018) which refers generally to the application of game-like characteristics (e.g. competition, score-keeping, etc.) to non-game (a.k.a. "serious") tasks. Although it may be difficult to conceive of gameplay as "gamification," we may cursorily describe our approach as "gaming the gamer" into contexts, situations, and opportunities for reflection and frame experimentation. Thus, while actual video gaming per-se would typically fall just outside the boundaries of gamification because there is no business task involved, we demonstrate in this study that video gaming 


\title{
Issues in Information Systems
}

\author{
Volume 22, Issue 2, pp. 1-20, 2021
}

can have the effect of increasing one's confidence in their ability to perform creative problem-solving which is a crucial characteristic of successful creative IS professionals and students (Couger et al., 1993; Tiwana and McLean, 2005). As such, problem-solving based video gaming can be used to "gamify" aspects of professional development.

Although the degree to which video games are associated with creativity as a general human capacity has been the subject of research (Green and Kaufman, 2015; Zackariasson et al., 2006), Creative Self Efficacy goes beyond creativity as characteristic or trait and examines capacities and potential for creativity as a reservoir and motivation for potential action-taking (Payne et al., 2018). It is also possible to focus on personal performance aspects of gaming, such as in how Flow Theory is used to explain how the gamified elements lead to heightened enjoyment, focused immersion, time disassociation, control, and curiosity which, in turn, lead to positive outcomes such as greater personal productivity (Csikszentmihalyi, 1988), online shopping (Koufaris, 2002), and learning (Admiraal, 2011). However, our interest is in how gaming may be used as a vehicle to shape and maintain practices to develop the capacity for creativity. In this sense, if gaming is a medium to develop creative competencies, when we would want to discern between the essences and accidents (Marcos, 2005) that shape the outcomes of gameplay when non-hedonistic ends are of interest. Answers may be found in specific player actions, decisions, successes, failures, and general psychological distance whilst engaged in game play. Thus, an understanding of why players make certain gameplay decisions may assist in using gameplay to achieve non-hedonistic and otherwise specific goalseeking outcomes of gameplay (e-sports notwithstanding). For example, if a game player completes a "level", was it intentional or accidental?

To better understand gameplay effects, we designed a qualitative study to 1) understand player intentions and thinking during gameplay, and 2) map those thoughts and intentions to theoretical principles and outcomes of learning and creative problem solving. To accomplish this, we performed an observational, qualitative study of players by recording and observing their gameplay and then reviewing video recordings of that gameplay. We followed this gameplay review with select interviews to understand their decisionmaking and learning.

Content analysis of game design and gameplay revealed underlying theories on construal-levels (Trope and Liberman, 2010), reflective practice (Schon, 1983; 1987), and tacit knowledge (Polyani, 1967) that provide a framework to understand problem-solving-based video gaming leads to improved confidence in one's creative problem-solving capabilities. Moreover, these theories provide the distinction between problemsolving, problem-setting, and problem-resetting as each having different requirements of Creative SelfEfficacy. Therefore, although our methodology is qualitative, we still adopt a quasi-positivist perspective. In other words, we began our exploration with no prior theoretical leaning or bias, but we found that the existing theories mentioned above are instructive and useful to explaining our results. Therefore, the remainder of the paper follows a traditional positivistic format in which we examine the following research questions: 1) How does game design influence players' problem-solving and problem-setting techniques? and 2) How does player problem-setting and -solving reveal their player archetypes?

In Section 2, we review prior research on the effects of video game playing on learning, creative problem solving, and self-efficacy. In Section 3, we review theory on construal levels and reflective practice and integrate them into a theoretical process-model that will explain our results. Section 4 presents our qualitative methodology and Section 5 details the results of our study that confirm the theoretical process model. In Section 6, we discuss the practical implications of our findings related to player archetypes and hiring potential. In Section 7, we discuss the limitations of our study. We present future research in Section 8 and summarize conclusions in Section 9. 


\title{
Issues in Information Systems
}

\author{
Volume 22, Issue 2, pp. 1-20, 2021
}

\section{Video Gaming Outcomes on Learning and Creative Problem Solving}

Video games exude an increased presence and influence in daily life and the societies in which we live (Shankar and Byus, 2003). Indeed, gamification and game-based learning have had an impact in the field of education and grown in use over the last decade (Subhash and Cudney, 2018). Although there are known negative effects of excessive video gaming such as addiction (Chiu et al., 2004; Smith, 2006; Ferguson, 2007), research has also shown a variety of positive effects (Ferguson, 2007; Granic et al., 2014; Greitmeyer and Oswald, 2010; Ryan et al., 2006). Researchers have more recently incorporated puzzle video games in educational environments, including Minecraft, Portal 2, and Crayon Physics Deluxe (Blanco-Herrera et al., 2019; Gallagher \& Grimm, 2018; Kao et al., 2017; Barr, 2019). In particular, players of these games demonstrated increased creativity and spatial abilities. Games have also been used to teach concepts in high school biology and disasters (Rüth \& Kaspar, 2020; Gampell et al., 2020). Research on games, game design, and games and learning have also incited work examining challenges of game research, including those that arise when measuring attitude changes toward video game content (Kolek et al., 2019). Video games have been used to explore issues in health as well and have had positive effects on older adults (Hall et al., 2012).

We are particularly interested in research that has demonstrated effects of video game playing on creativity and problem-solving skills. While this research is limited, there are several studies of note. Many experiments have been conducted using video games with positive results, including improvements in memory, engagement, information processing, and learning (Chuang \& Chen, 2007; Powers et al., 2013; Ibáñez et al., 2014; Hamari et al., 2016). Improvements in problem-solving have also been found as a result of playing strategic video games (Squire, 2008; Adachi \& Willoughby, 2013). In one study of product design, Cooper et al. found that participants could solve complex problems in a gaming environment that they might not otherwise be able to solve (2010). Positive effects of video games have also been observed on K-12 mathematics and reading assessments (Bowers \& Berland, 2013).

While these studies make clear an association between problem-solving and video game play (both recreational and professional), they do not fully to identify the 'why' behind this achievement and what exactly is happening in the minds of those playing. Other studies have identified the impacts of video games via physiological examinations (e.g. fMRI study, physical examination study), noting what parts of the brain are active during gaming and the physical stresses during gaming (Ravaja et al., 2006; Mathiak \& Weber, 2006; Hoeft et al., 2008). These studies provide vital insight into blood flows through the brain during gameplay; however, they do not explain the actual thought process, intentions, and decision-making process. In addition, most of the prior research typically relies on variance theories which do not account for learning and development processes.

Furthermore, part of the reason that prior research has left a theoretical gap is because these studies have primarily focused on the effect of video games directly on learning and problem-solving performance and behaviors. While useful, we believe it is more appropriate in the context of CrISPs to examine the effects on self-efficacy (Bandura, 1982) which is already strongly linked to behavior and task performance. In particular, creative self-efficacy (CreaSE) - one's confidence in her or his ability to solve unstructured IS problems with creative information technology-based solutions (Payne et al., 2018) - is the primary outcome of interest in our context. If video gameplay is going to translate into improved business problem solving, then it will occur less through the development of technology skills and more through the increase in one's confidence in their creative problem-solving abilities and, thus, by improving one's ability to cope with unstructured environments.

Therefore, we proceed by reviewing theory on construal levels (Trope and Liberman, 2010), reflective practice (Schon, 1993), and self-efficacy (Bandura, 1982) which we integrated into a process model to 


\section{Issues in Information Systems}

Volume 22, Issue 2, pp. 1-20, 2021

explain how video gameplay experience can lead to learning and confidence improvements with creative problem-solving. Further, we transition from considering problem-solving alone-an ability to find familiar frames and solutions to a problem - to also considering problem-setting, or an ability to experiment and select from new candidate frames and solutions to an emergent problem or a familiar problem that requires new perspective.

\section{Towards Reliable Creativity: Reflective Practice for Repertoire Development}

In this section, we describe a theoretical model that positions video games as tools that can be used to develop the habits that enable Creative IS Professionals (CrISPs) to respond masterfully to emergent IS challenges in need of creative IS solutions. The model, illustrated in Figure 1, is composed of existing theory related to Construal, Reflective, and Tacit (CRT) systems and was synthesized via content analysis of participants' gameplay and interviews.

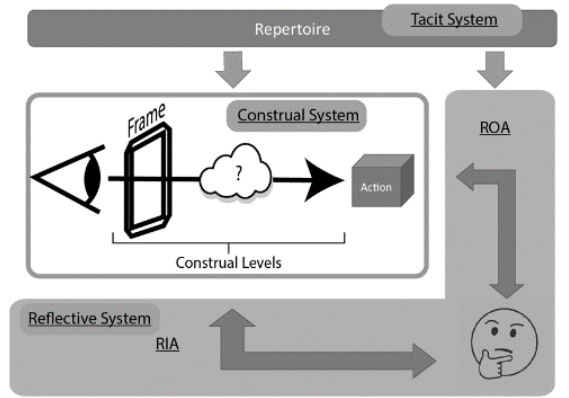

Figure 1. Construal, Reflective, and Tacit Systems Model (CRT)

The CrISP faces an emergent set of challenges in the organizational and computational nexus that frequently requires talents that exceed problem-solving, even creative problem-solving. As IS problems typically involve some element of design, many of the challenges inherent to design require an ability to address the following: complexity, systems thinking, communication, information processing, modeling, and knowledge management. When a problem exudes familiar and easily recognized characteristics, a rational approach is usually immediately available to a professional and operationalized. We generally characterize this process as problem-solving. However, for many problems, the challenge is not the solving of a familiar problem, but the framing of an unfamiliar problem adequately such that known and rational problemsolving techniques can be applied. In these cases, the CrISP may need to shift to what Schon (1993) calls "problem setting." To set a problem, one must approach it with candidate frames that each apply a palette of metaphorical sense-making as a means of "seeing" and comprehending the novel and emergent phenomenon.

The CrISP frequently engages in problem solving. However, it is problem setting, rather than problem solving, that is of greater importance when confronting unstructured or unfamiliar problems. A familiar problem frame may not be readily available to the CrISP when they are presented with emergent phenomena. However, problems emerge within a problem domain and context that can suggest familiar frames or allow for reframing when a familiar frame either no longer resonates or no longer facilitates a feasible solution (Schon, 1993). Thus, a second case exists where the familiar requires reframing to comprehend the familiar from a new frame.

Problem setting requires a degree of creative skill, barring the flukes of blind luck, to effectively select from possible frames in a rapid succession of frame experiments designed to increase comprehension (Rein and Schon, 1995). If a professional context is assumed, where the open-endedness of experimentation for 


\title{
Issues in Information Systems
}

\author{
Volume 22, Issue 2, pp. 1-20, 2021
}

learning must be hastened for goal-seeking and/or profit motives, then a degree of coping and confidencebuilding operating behaviors are useful to ensure the masterful application of frame experimentation. Relatedly, Bandura (1982) has suggested that self-efficacy is a mental frame under which masterful action is well-facilitated. The frame setting must also select from a variety of candidate frames in search of a viable and successful frame. A CrISP must possess high confidence in their creative capacity to move from candidate frames to successful frames, with high reliability. This is the process by which possible solutions are explored and applied mentally to the problem space until a successful problem-solving approach is found.

Frame selection is facilitated by the familiarity and resonance that the emergent phenomenon makes with the CrISP's experience and their familiarity with the problem context. Thus, a psychological distance will exist when the phenomenon is first encountered. Construal Level Theory (Trope and Liberman, 2010) holds that initial understanding has greater psychological distance and operates at high-level construal. Construal "levels" explain why initial and/or uncertain comprehension of phenomena happens at higher and more abstract levels. Assuming psychological distance can be reduced over time and in negotiation with the phenomena, then comprehension, (re)cognition, and action strategies will operate at lower and concrete levels. Using Construal Level Theory, we posit that experimenting with candidate frames will shorten psychological distance and create lower-level construal. Further, in the case of extant phenomena in need of problem resetting, it may be necessary to create increased psychological distance for new perspective before the distance can then be shorted once again. Thus, the increased psychological distance demonstrates even greater self-efficacy on the part of the CrISP as they deliberately depart the familiar in search of the unfamiliar.

What is learned from exercising this human capability has the potential for future use as a part of one's tacit knowledge (Polyani, 1967). However, the mental models one draws from are not uniform in composition and therefore are not equally available for action in terms of their shape and acuity. The mechanic at play then is the ability to create and modify mental models of phenomena via new experiences in a construal process. Construal Level Theory proposes that the psychological comprehension of both novel and familiar phenomena creates psychological distance in comprehension that can be characterized as running in a spectrum from abstract to concrete (Trope and Liberman, 2010). This "distance" can be temporal, spatial, hypothetical, or any other valid mode of reasoning that accommodates sense-making. Other possible distances may be informational, experiential, or affective.

The CrISP's toolkit must contain the ability to translate construal level and psychological distance control into self-efficacy that leads to enactive mastery. Thus, a daily professional practice designed to foster the journey towards mastery would be effective at attaining and maintaining high self-efficacy in the process of problem-setting and problem-resetting. A key component in such a habit would be mindful cognition of the frame selection process as it is happening. This habit is the component of reflective practice (Schon, 1983; 1987) termed "reflection-in-action." In a professional context, where the latent availability of impactful action from tacit knowledge must be of a higher reliability, self-efficacy matters most in terms of committing to planning and strategic allocation of resources. Thus, while the judgments, stereotyping, categorization, social distance and power, and self-regulation all modify the perceptions that surround construal levels, in a professional context, it may be necessary to capitalize on construal levels and seek to enhance them to increase the availability of tacit knowledge in what Schon (1983) has referred to as "repertoire." Table 1 shows the elements of reflective practice as they may be applied to video game design. 


\section{Issues in Information Systems}

Volume 22, Issue 2, pp. 1-20, 2021

Table 1. Elements of Reflective Practice Applied to Game Design (Schon, 1983, 1987)

\begin{tabular}{|l|l|}
\hline Reflective Practice & Application \\
\hline $\begin{array}{l}\text { Tacit Knowledge } \\
\text { Acquisition }\end{array}$ & $\begin{array}{l}\text { Familiarizing oneself with the game environment through movement without } \\
\text { making an explicit attempt to solve a puzzle through action }\end{array}$ \\
\hline Repertoire Development & $\begin{array}{l}\text { Explicit understanding of a new game rule or skill that can be applied to } \\
\text { solving puzzle rooms in the game }\end{array}$ \\
\hline Repertoire Use & Application of a new game rule or skill acquired via Repertoire Development \\
\hline Reflection in Action & $\begin{array}{l}\text { Explicit decision to try a different puzzle strategy in the middle of one puzzle } \\
\text { room }\end{array}$ \\
\hline Reflection on Action & $\begin{array}{l}\text { 1. Reflection on the player's puzzle solving strategy as it was applied at } \\
\text { a post-puzzle sign (confirmed via interview) } \\
\text { 2. Demonstrated by visiting the Main Hub and returning to the same } \\
\text { puzzle to try a different solution (confirmed via interview) }\end{array}$ \\
$\begin{array}{l}\text { 3. Reflection on player's puzzle solving strategy during the interview } \\
\text { that the player did NOT have during the game }\end{array}$ \\
\hline
\end{tabular}

Schon suggests further that the process by which professionals may engage in successful repertoire use, which positively impacts construal levels and self-efficacy, is to discipline deterministic behaviors in the face of the unpredictability of perception. Reflective practice, an openness to in-the-moment reflective awareness and a discipline to engage in post-hoc reflective habit has been presented as one means of increasing the availability of repertoire. Further, we posit that reflective practice may improve tacit knowledge development and availability - repertoire - such that improvements in construal levels may serve as a means of capitalizing on self-efficacy via repertoire availability and success. Further, the reliable use of repertoire, particularly in a professional context, may lead to that professional's ability to achieve the mental state where tacit knowledge utilization, through repertoire recall and application, is most effective and most influences construal level maintenance. For professionals, those who must apply their skills on command and with regularity, a discipline must surround the construal levels and repertoire use and development that go beyond the ephemerality that is characterized by sentiments such as "inspired, when I feel like it, or in the mood." Thus, the flow necessary to utilize managed repertoire use comes about from a discipline that Schon calls reflective practice. The Tacit System represents the repertoire of the professional gained from past experience. This repertoire informs both the Construal and Reflective systems. The Construal system uses the repertoire of the Tacit system to engage in the successful framing and reframing process needed to overcome psychological distance and approach a problem with a familiar frame.

After providing the details of our methodology, we introduce the game design of Antichamber as the context within which we observe the interactions between the Tacit, Construal, and Reflective Systems. The theory of entrainment provides evidence that learned reflective practice induced by game design in players will transfer successfully to other modalities, including that of the CrISP (Ancona and Chong, 1996). 


\section{Methodology}

\section{Observational Study Procedures}

Two hundred and three (203) participants played the game for forty minutes with the objective of visiting as many puzzle rooms as possible. Videos of the participants' gameplay were recorded using Open Broadcaster Software (OBS). As the authors reviewed the videos, a live commentary was also recorded of the author's interpretation of the participants' gameplay through each puzzle/room of the game (up to 67). As the author reviewed each video, they recorded: 1) what the participant was trying to accomplish, 2) why the participant wanted to accomplish that action (what the likely goal would be), and 3) why the participant likely believed that action would achieve the goal. Importantly, this procedure was not intended to be fully conclusive. Rather, these initial author recordings were used to identify candidates who represented various backgrounds in video game experience/repertoire and capacities for reflective practice.

After an initial review of all gameplay video recordings was conducted, the original set of participants was requested to follow up with a subsequent interview. Five participants were selected to interview based on their prior gaming experiences. These participants were chosen from the following gaming domains presented in game literature: 1) Casual Puzzle Games, 2) Casual Party Games, 3) First Person Shooter Games, 4) Role-Playing Games, and 5) Action/Adventure Games (Nelson and Strachan, 2009; Quick and Atkinson, 2011). None of the participants selected had played Antichamber before the study. The author that provided commentary on the participants' gameplay conducted the interviews. The identities of the participants were not known to the interviewer prior to each interview.

\section{The Interviews}

The interviews were conducted via the collaborative meeting software Zoom and recorded with Open Broadcaster Software (OBS). During each interview, the participants were first asked a series of questions related to their gaming and academic backgrounds before being shown a video recording (without audio) of their gameplay. The interviewer played the recording back and paused as needed to question the participants about their strategy, thought processes, and affect during gameplay as they progressed through the puzzle rooms in Antichamber.

Interview questions were selected with the intention of accomplishing the following goals: 1) eliciting information from the player related to their general experiences with problem-setting and problem-solving, 2) eliciting information from the player related to their general affect towards problem-setting and problemsolving, 3) confirming observations made during commentary of gameplay, 4) eliciting information from the player related to their experiences with problem-setting and problem-solving in Antichamber, and 5) eliciting information from the player related to their affect towards problem-setting and problem-solving in Antichamber. These interview questions related to academic background, video game background, and strategies used in Antichamber are designed to elicit how game design may influence players' problemsolving and problem-setting, and how player problem-setting and -solving reveals their player archetypes.

\section{Content Analysis of Antichamber, Gameplay, and Interviews}

At the conclusion of the interviews, the authors began content analysis of participants' gameplay and interviews. The initial open and selective coding procedures resulted in the selection of an appropriate theoretical model in the form of CRT, as well as the classification of each participant into categories based on previous video game experience, Dreyfus' (1980) model of skill acquisition as it applies to video games 


\section{Issues in Information Systems}

Volume 22, Issue 2, pp. 1-20, 2021

and capacity for reflective practice, shown in Table 2 . The game titles mentioned by each participant are and classified on distinguishing dimensions that are drawn from prior research on video game taxonomy (Nelson and Strachan, 2009; Quick and Atkinson, 2011). Based on our coding of the participants' gameplay and interviews, we categorized them according to video game repertoire and capacity for reflective practice. Participants with a high capacity for Reflective Practice can be characterized by the effects that this capacity has on their Tacit and Construal Systems and its realization in Antichamber gameplay. These participants are able to engage frequently in reflection-in-action and reflection-on-action that in turn 1) increase the flexibility of their construal distance to enable more fluidity of problem resetting and 2) add new in-game problem solving strategies to their repertoire.

Table 2. Player Archetypes by Gaming Repertoire and Capacity for Reflective Practice

\begin{tabular}{|l|c|c|c|c|}
\hline \multirow{2}{*}{} & \multicolumn{3}{|c|}{ General Video Game Repertoire } \\
\cline { 3 - 5 } & high & moderate & low \\
\hline \multirow{3}{*}{ Capacity for Reflective Practice } & high & Reflective Expert & Reflective Competent & \\
\cline { 2 - 5 } & moderate & Flexible Expert & & Flexible Novice \\
\cline { 2 - 5 } & low & Inflexible Expert & & \\
\hline
\end{tabular}

The participants' prior video game experience also plays a key role in their capacity for Reflective Practice and the application of their Construal System, as is illustrated in our analysis. The key skills required to complete the game objectives are of particular importance in this regard, as players with experience playing only first-person shooter games will have a vast repertoire of games that require movement, aiming, and some strategic skill within a first-person perspective. Players with experience playing mainly puzzleplatformer or action-adventure games, on the other hand, are equipped with great attention to environment details and curiosity to explore a game environment to collect items and complete objectives related to exploration. The combination of high, moderate, or low capacity for reflective practice and high, moderate, or low video game repertoire produces the five player archetypes shown in Table 3 . The nuggets included for each player archetype were selected as part of the selective coding process of the interviews. We provide in-depth analysis each players' experiences applying the Tacit, Construal, and Reflective Systems while playing the game Antichamber. The results of our observational study are provided in the next section. 


\section{Issues in Information Systems}

Volume 22, Issue 2, pp. 1-20, 2021

Table 3. Player Archetype Characterization

\begin{tabular}{|l|l|}
\hline Player & Nugget \\
\hline Reflective Expert & $\begin{array}{l}\text { "I just kinda always assume puzzles like this have some solution, I'm just not } \\
\text { figuring it out. So I was just, I just figured I'd just kinda keep trying." }\end{array}$ \\
\hline Flexible Expert & $\begin{array}{l}\text { "There's kind of a learning curve, and some of the clues were kinda in your face } \\
\text { after you accidentally figured them out, but then it was almost like, 'Okay this is } \\
\text { doable. It's just a lot of trial and error." }\end{array}$ \\
\hline Inflexible Expert & $\begin{array}{l}\text { "It's not gonna be a skill-based game, is what I was first thinking. I was like, 'Okay } \\
\text { I'm not gonna be judged necessarily on how skilled I am in gaming, but more about } \\
\text { how I'm thinking. It's gonna be a puzzle game." }\end{array}$ \\
\hline Reflective Competent & $\begin{array}{l}\text { "How would you describe this game?" "I'd probably say it was like a puzzle game } \\
\text { where the environment is the puzzle...And so it's... Like you're trying to figure out } \\
\text { how to work in a reality that doesn't parallel our own. It has different rules....so you } \\
\text { have to figure out what the rules are." }\end{array}$ \\
\hline Flexible Novice & $\begin{array}{l}\text { "So can you talk a little bit more about that, like why was it fun, a little bit?" } \\
\text { "Well, once I figured out I could block the lasers and then use the block to block the } \\
\text { lasers... And now that I realize that I didn't figure that out, I feel kind of dumb, but } \\
\text { it's fine." "Was it more fun the more stuff you knew how to do?" "Yeah." }\end{array}$ \\
\hline
\end{tabular}

\section{Results}

\section{Results of Content Analysis of Gameplay and Interviews}

In this section, we provide an in-depth discussion of the results of our content analysis. The results of coding gameplay and interviews are best understood in the context of Antichamber itself as a game designed to test and manipulate players' problem-setting and -solving techniques. Thus, we first define the research context with a discussion of Antichamber, including the intentions of its designer and the key components of the game design as they are related to our research questions. To review, the purpose of our investigation is to explore how game design may influence players' problem-solving and problem-setting techniques and how player problem-setting and -solving reveals and refines player archetypes. After defining the context of Antichamber and demonstrating how its key components are relevant to our research questions, we detail our coding of each players' gameplay and interview responses.

\section{Antichamber: An Overview}

Antichamber is a first-person puzzle and exploration video game for PC released in 2013 on the Steam platform. It was developed by independent game developer Alexander Bruce, whose vision for the game was that of a single-player game with spaces and puzzles in which the "player would have to work out how the rules work" (Carless 2011). One of the most prominent features of the game is the inclusion of 3D instantiations of what are known as "impossible objects," or structures that could not occur within normal three-dimensional space. Bruce has stated that "breaking down all those expectations and then remaking them is essentially the core mechanic of the game" (Totilo 2011). The "expectations" described by Bruce are that the spaces the player explores in the game can be navigated and behave like Euclidean spaces encountered in most other first-person perspective game environments. To successfully explore all of the 


\title{
Issues in Information Systems
}

\author{
Volume 22, Issue 2, pp. 1-20, 2021
}

rooms in Antichamber, the player must break down these expectations and develop a new repertoire of mechanics to navigate the non-Euclidean and otherwise unfamiliar spaces of the game.

There are three key components of the game, including 1) the Puzzle Rooms, 2) the Signs, and 3) the Main Hub. Each of these game components facilitates the processing of the systems in the CRT theoretical model described earlier. In the following section, we explain in further detail the key components of the game Antichamber as they relate to the interactions between the Tacit, Construal, and Reflective systems.

\section{The Puzzle Rooms}

The object of Antichamber is to explore all of the puzzle rooms and, in doing so, escape. Thus, the puzzle rooms provide the context in which the players must problem solve. Each puzzle room requires the player to choose a problem-solving strategy and to apply it to the environment to advance. Each problem-solving strategy selected by the player represents a frame as described in the theoretical model. The application of a problem-solving strategy in a puzzle room is the choice of a frame within the context of the room that emerges from the interactions between the Tacit, Construal, and Reflective Systems via problem setting or problem resetting. In both cases, the player arrives in one of the puzzle rooms and, drawing upon the repertoire of the Tacit System, is affected by their construal distance from the environment of the puzzle room. The player's Tacit System is comprised of a combination of 1) tacit knowledge and repertoire acquired via previous video game experience, 2) their understanding of Euclidean spaces, 3) and new tacit knowledge and repertoire acquired while playing Antichamber.

When the game begins, a player is equipped with only 1) and 2) above. In addition to video game experience, players will have preconceived ideas about how Euclidean space can be navigated and their construal distance from the problems presented in such spaces may be short without additional game context. Players are also equipped with repertoire and tacit knowledge from video games they have played previously that will affect their construal distance within the puzzle rooms. For example, a player with experience navigating game environments in the first-person perspective may initially have a short construal distance from the puzzles presented in the rooms. We explore how a player's repertoire of video game experience and affinity affects their construal distance, potential for successful problem setting and problem resetting, and potential for reflection-in-action and reflection-on-action in Section 3. To illustrate the problem setting and resetting process that players may undertake in Antichamber and provide context for the results of our observational study, we explain the most common progression of players through one puzzle room in greater detail.

\section{Player Progression through Leap of Faith}

There are three ways of progressing through the puzzle called "Leap of Faith," two of which are achieved by attempting to jump the gap and falling into the gap as a result. Given the context of crossing a large gap, however, falling is likely to be perceived as failure to solve the puzzle room and the application of an unsuccessful frame. To cross the gap, the player must hold the Shift key and walk across to get to the distant ledge. This solution is not obvious, however, and the player is likely to need additional feedback from the game to problem reset and select this frame. To this end, the developer provides several clues as the player progresses, most notably including the Signs. The results of our coding indicated that the archetypes with high video game repertoire, including the Reflective Expert, the Flexible Expert, and the Inflexible Expert, use that repertoire to select candidate frames and assume that they will not make the jump. The high capacity for reflective practice archetype, the Reflective Expert, modifies the assumption with a test of the controls to make sure that the gap cannot be crossed. The archetypes with moderate and low video game repertoire accept the candidate frame given by the game design and attempt to jump the gap without considering that they will not make it. The attitude of each archetype towards this puzzle room is in harmony with both level 


\title{
Issues in Information Systems
}

\author{
Volume 22, Issue 2, pp. 1-20, 2021
}

of video game repertoire and capacity for reflective practice. To further analyze each archetype, their responses to the Signs was also an important consideration.

\section{The Signs}

The Signs are one of the most important components of the game because of their potential to activate reflection-in-action and reflection-on-action via the player's Reflective System. As an example, when the player falls from Leap of Faith to the ground floor, they are presented with a sign that states "Failing to succeed does not mean failing to progress." The placement of the sign after these events makes it a great potential mechanism for inducing reflection-on-action in the player. The player has chosen what is perceived to be an unsuccessful frame for crossing the gap and is told that progression may occur regardless of success. The occurrence of the sign after and away from the Leap of Faith puzzle room give it the potential to induce reflection-on-action rather than reflection-in-action. The player archetypes' treatment of the signs demonstrated evidence of both their level of video game repertoire and their capacity for reflective practice. The archetypes with high capacity for reflective practice, including the Reflective Expert and Reflective Competent, viewed the signs as both useful and positive game elements. Archetypes with low to moderate reflective practice capacity, in contrast, found the signs "mocking" or "taunting." This difference in affect towards the Signs among the archetypes suggests that those with positive experiences demonstrate greater problem-setting abilities than those with negative experiences. It should be noted, however, that for the player's Reflective System to engage they must choose to click and read the sign, as the game does not require that the signs be read. Additionally, the player must choose on their own to reflect and make the connection between the sign and its associated puzzle room. Thus, while the Signs provide a vehicle for reflection-in-action and reflection-on-action, it is not guaranteed that their presence will activate the player's Reflective System.

\section{The Main Hub}

In the Main Hub, the player can choose to visit any puzzle they visited previously by clicking its location on the Map. When the player chooses a location on the map in the Main Hub, they may do so with the intent of 1) attempting to solve an unsolved puzzle with a previously applied problem-solving strategy, 2) reapplying a successful problem-solving strategy to solve a puzzle that has been already solved, or 3) attempting to solve an unsolved puzzle with a new problem-solving strategy. Because it is distinct in design and physically separate from the puzzle rooms in the game, when the player spends time in the Main Hub they exist outside of the context of the problem-solving environment of Antichamber. The distance and distinction of the Main Hub enables the player to lengthen their construal distance from the puzzle rooms in the game. As a result, the player has the potential to generate new candidate frames for any of the puzzle rooms they have visited previously via problem resetting induced by reflection-on-action.

Archetypes' level of game experience and capacity for reflective practice influenced their perception of the Main Hub. Of note is the response of the Flexible Expert, whose initial perception was that the room was a "failure room." Here, his level of competency in video games made him feel that leaving a puzzle unfinished and using the escape key to enter the Main Hub was indicative of failure. However, his moderate level of reflective practice capacity enabled him to reframe the Main Hub as merely a map of choices rather than a "failure room." This reframing gave him the confidence needed to pursue the completion of additional puzzles he may have avoided based on the belief that he needed to solve Leap of Faith before moving on. Other archetypes' experiences varied based on their combination of reflective practice capacity and video game repertoire. High video game repertoire enabled faster perception of the semiotics of the Main Hub, including nodes leading to unfinished puzzle rooms. High reflective capacity resulted in either a test to see how long the use of the escape key could be avoided or a slower recognition of the meaning of symbols on 


\section{Issues in Information Systems}

Volume 22, Issue 2, pp. 1-20, 2021

the map. In general, archetypes' use of and affect towards the Main Hub provided evidence of their problem-setting ability and reflective practice capacity.

Table 1: Means and Standard Deviations for Gender

\begin{tabular}{|l|r|r|r|r|}
\hline & \multicolumn{1}{|c|}{$\mathrm{N}$} & \multicolumn{1}{l|}{ Mean } & Std. Deviation & Std. Error \\
\hline Female & 81 & 5.2222 & 1.31992 & .14666 \\
\hline Male & 83 & 5.2319 & 1.16267 & .12762 \\
\hline Total & 164 & 5.2271 & 1.23901 & .09675 \\
\hline
\end{tabular}

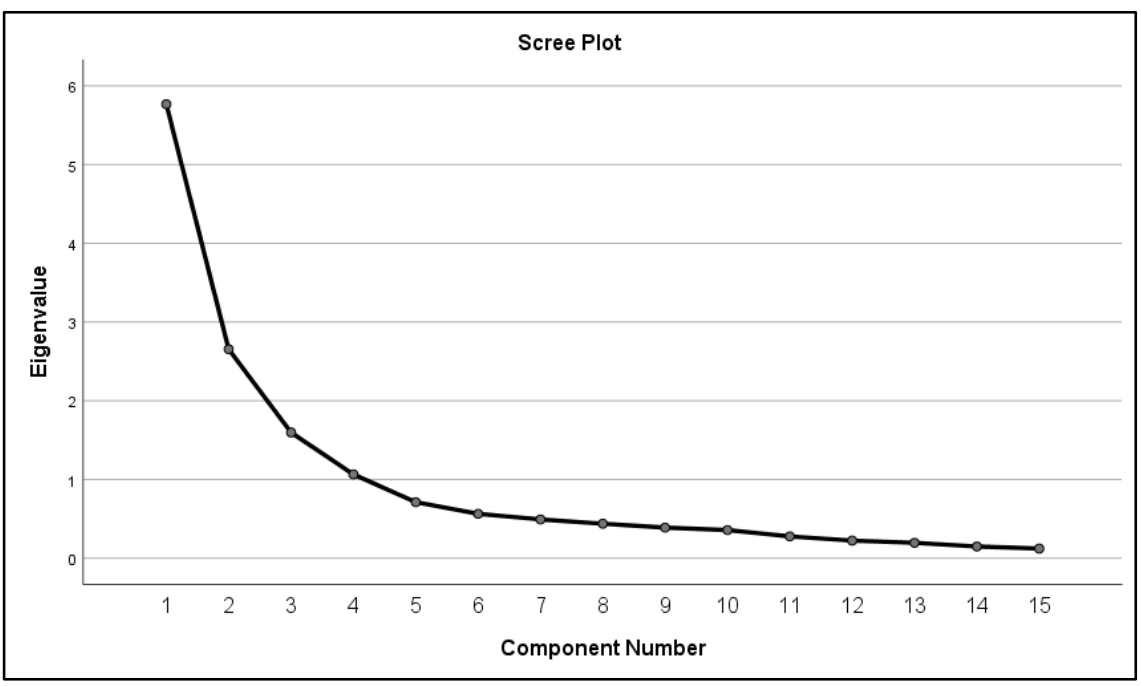

Figure 1: Scree Plot Test

\section{Discussion}

The observation of several players in the context of Antichamber provided answers to our research questions related to how gameplay reveals player archetypes and the effects of the game on those archetypes. Additionally, we saw that as in serious games applications, the familiar mechanics of video games can be repurposed. What we have explored in this research is the degree to which the mechanics and structures of video games can induce problem-setting and -resetting behaviors as a means to conduct frame experiments rather than frame recall. If we consider the behaviors and reflections of the gamers from our study, we see support for our assertion that a reflective system can assist in calibrating and controlling the construal system. As such, the players that showed more capacity for reflective practice made more progress overall in the game as their frame experimentation was both more available and more fluidly and adeptly utilized. These results are presented in Figure 2. We find that the fluidity of frame experimentation is suggestive of higher levels of CreaSE. The context of repertoire use also matters as the type of player also influenced progress in the puzzle rooms explored in Antichamber. Taken together, we see that levels of CreaSE and player archetype worked together to influence capability for reflective practice. Overall, and perhaps not surprising, we find that the Reflective Expert demonstrated the highest capacity for reflective 


\section{Issues in Information Systems}

Volume 22, Issue 2, pp. 1-20, 2021

practice and problem setting. From observations and interviews, this player had more contextual repertoire in problem setting and resetting to draw from in terms of approaching puzzle games. We contend that puzzle games are a reasonable proxy for the kinds of problems that the CrISP would most typically face. In this sense, the players that showed more capacity for reflective practice were able to do more successful problem resetting via managing construal levels in their frame experimentation.

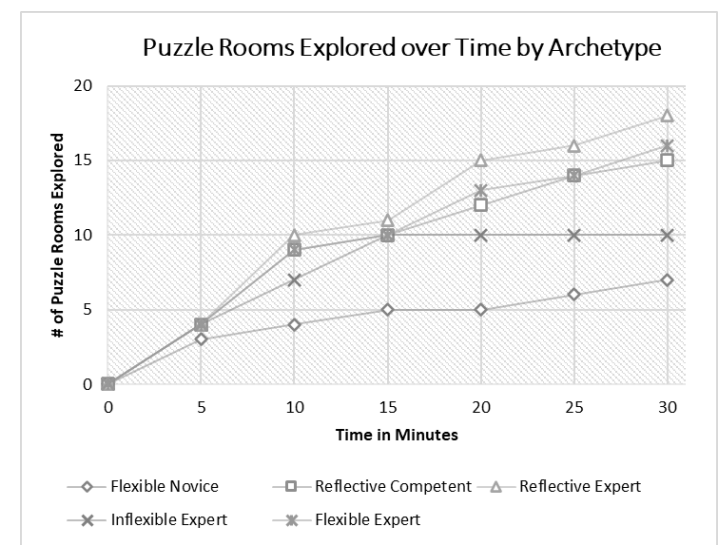

Figure 2. Puzzle Rooms Explored over Time by Archetype

\section{Practical Implications}

Although many stakeholders and constituents touched by an information systems challenge would benefit from the knowledge and skills of the CrISP, we would most directly address they that search for and manage the CrISP. The player archetypes identified and discussed in this work provide an opportunity to make prescriptions based on the cases we examined. Thus, if we were to make hiring suggestions based on our results, we can select from a number of dimensions examined in our study as the basis of our recommendations, including gameplay style classifications and the nature of the tasks along the continuum of problem-setting vs. problem-solving. The player archetypes revealed in this study were measured on the dimensions of 1) capacity for reflective practice and 2) video game experience/competence. The combination of these measures produced five archetypes. Each archetype is described below with respect to the measures from Dreyfus (1980) and explained from the perspective of hiring potential. Potential future work regarding results from the analysis of each archetype is also suggested.

\section{Flexible Novice}

The Flexible Novice archetype combines a low level of video game experience and skill with a moderate capacity for reflective practice. This player approached the problem space from a naivete such that exploration was borderline amethodical. It was tempting to comprehend this lack of bias in frame selection as being akin to that of the Reflective Expert archetype, but these observations were found to be highly probable of Type I Error. There was no discernible system of repertoire use and reflection such that prior success was captured as actionable tacit knowledge. It is possible that partnering this archetype with another could compensate for deficiencies in either archetype. Future work in this area might consider how the pairing of a Flexible Novice with an Inflexible Expert could improve overall performance on structured and unstructured tasks.

\section{Reflective Competent}

The Reflective Competent archetype combines a moderate level of video game experience and skill with a high capacity for reflective practice. This player demonstrated a high capacity for reflective practice and 


\title{
Issues in Information Systems
}

\author{
Volume 22, Issue 2, pp. 1-20, 2021
}

problem setting such that construal level was malleable and problem-solving skills observed were sufficient. This is a hire whose skill level might not be at the top of the heap, but whose capacity for reflective practice would position them well in roles where problem setting is valuable. Pairing this archetype with the Inflexible Expert would provide value. Future work in this area might consider how additional specialized training on tasks may improve the efficacy of the Reflective Competent overall when solving unstructured problems.

\section{Inflexible Expert}

The Inflexible Expert archetype combines a high level of video game experience and skill with a low capacity for reflective practice. Type I Error is also an issue when a player archetype is unwilling to explore far from familiar frames. Psychological distance is also created from an overconfidence where frames outside of those that are familiar are construed to be of lesser value or importance. This is a problem-solver at best where a well-known and well described task, that is contextually relevant, has been specifically described. This archetype would do well with well-defined tasks. The interesting research question that arises from the experience of the Inflexible Expert is one of how capacity for reflective practice can be improved. Further research in this area might consider adapting the experience of Antichamber to better suit the strengths of this archetype.

\section{Flexible Expert}

The Flexible Expert archetype combines a high level of video game experience and skill with a moderate capacity for reflective practice. This player suffered from Type II Error, but still exhibited good frame recognition in problem solving. The benefits of reflective practice would likely have a good effect. However, although our observations and interview coding suggest that CreaSE was lower with this player, the capacity to work well with others and consider other viewpoints held promise for reflective practice accrual. Future work in this area might consider how confidence in one's own problem-solving abilities and potential for problem resetting are related.

\section{Reflective Expert}

The Reflective Expert archetype combines a high level of video game experience and skill with a high capacity for reflective practice. This player brings both a vast gaming repertoire and ability to reframe contexts via problem setting to Antichamber gameplay. We would generally prioritize the Reflective Expert above others as the contextual repertoire is rich and construal level management should be more readily available. Problem setting is a primary skill for this archetype and familiarity with frame experimentation should quickly identify appropriate frame approaches based on pattern recognition. The capacity to embrace and benefit from reflective practice was highest with this player archetype. The Reflective Expert would serve and be well-served in roles in which problem-setting is necessary to produce positive outcomes. Placing this archetype in roles limited to problem-setting may lead to job unsatisfaction and burnout. Further work in this area might consider how the problem-setting abilities of the Reflective Expert could be operationalized, extracted, or taught to other archetypes lacking in capacity for reflective practice.

\section{Study Limitations}

The player archetypes presented here are currently described in a far more notional manner arising from the context of this single study. A more comprehensive study could be designed to gather a wider group from which observations and interviews could be culled. As such, although we describe thorough coding procedures that are consistent with content analysis, a wider set of interviews could extend and strengthen 


\title{
Issues in Information Systems
}

\author{
Volume 22, Issue 2, pp. 1-20, 2021
}

both our findings and the veracity of our framework. However, our study provides sufficient evidence that gameplay can be used as an accurate indicator of player intentions. This confirmatory finding provides the foundation for additional coding of gameplay and further exploration of player archetypes.

Further, while Antichamber is a unique gaming experience which fits the premise of our study well, not all puzzle games exhibit the depth and purpose presented in Antichamber. Alexander Bruce designed the puzzles of Antichamber with the intent of provoking reflective practice in its players. While other game designers may not share Bruce's intentions, however, their games may still produce the effects of the CRT model in players' knowledge acquisition, adjustment of construal levels, and reflective practice during gameplay. Investigating the generalizability of the CRT model in video game design is indeed important future work. Lastly, since at least some of the justification for the design of our study is to increase CreaSE, then some latent variables to serve as dependent variables could inform a subsequent variance model used to test the premises of the CRT process model. One such dependent variable could be flow, which is commonly discussed in the gaming and gamification literature as it relates to performance on tasks (Csikszentmihalyi, 1988).

\section{Future Work}

Initial content analysis of the game Antichamber revealed a set of player archetypes representative of capacity for reflective practice and gaming repertoire. The process of interviewing five participants selected by gaming experience revealed the nature of the CRT model and its application in Antichamber. More importantly, the interviewing process validated the concept of coding gameplay as player intent. Confirmation that actions taken by players in games can be coded and representative of thoughts and intentions suggests that further qualitative research in the video game domain is promising to better understand its practical applications.

Our first enterprise will be to use the selective codes from this study and the resultant CRT model to code the remaining Antichamber participant data. This procedure will likely result in additional player archetypes and further insight into how these new archetypes problem set and problem solve. The next step will be to investigate how CreaSE can be most effectively manipulated for each player archetype.

Finally, one of the primary goals of this work is the application of elements of game design to education. Much work has been done in the area of gamification, as game-like elements including badges and "leveling" have been applied to classroom environments to improve motivation and learning (Subhash and Cudney, 2018). Our aim, however, is to understand how game design influences players' problem-setting and -solving techniques and apply that insight to the design and development of problem-based learning environments in the information systems domain. In their book, Rules of Play, Tekinbas and Zimmerman state that "the goal of successful game design is the creation of meaningful play" that "emerges from the relationship between player action and system outcome" (2003). We have observed meaningful play in the form of CRT in Antichamber and intend to explore other video game environments for evidence of its generalizability in the interactions between player archetypes and game design to bridge the gap between "player/game" and "learner/learning environment."

\section{Conclusion}

In this study, we explored two main ideas: 1) that the components of reflective practice and the CRT model could be mapped to game design and 2) that player experience with these components not only affects levels of CreaSE, but reveals their player archetype and, in turn, their approach to problem setting and solving. The implications of this work are relevant to hiring managers that need to suit hires to roles that require both problem setting and solving, as well as to educators that need to suit curriculum design to 


\section{Issues in Information Systems}

Volume 22, Issue 2, pp. 1-20, 2021

various student archetypes. The results of our analysis help answer our research questions as to whether gameplay could be representative of player intent and how that gameplay could be interpreted within a theoretical model related to reflective practice. The capacity to problem solve will always be an important skill, and training students and professionals to perform well when completing relevant tasks continues to be a primary goal of education. However, the value of problem setting cannot be understated or ignored in the swiftly and ever-changing emergent environment in which we live. The aim of our work is to not only be able to recognize the capacity for reflective practice in a gaming environment, but to create environments in which CreaSE and reflective practice can be learned and mastered. It is our hope with future research that we may be able to design games that detect and refine these important skills.

\section{References}

Adachi, P. J. C., \& Willoughby, T. (2013). More than just fun and games: The longitudinal relationships between strategic video games, self-reported problem solving skills, and academic grades. Journal of Youth and Adolescence, 42(7), pp. 1041-1052.

Admiraal, W., Huizenga, J., Akkerman, S. and ten Dam, G. (2011). The concept of flow in collaborative game-based learning. Computers in human behavior, 27, 1185-1194.

Ancona, D., \& Chong, C. (1996). Entrainment: Pace, cycle, and rhythm in organizational behavior. Research in organizational behavior, 18, pp. 251-284. Argyris, C., \& Schon, D. A. (1974). Theory in practice: Increasing professional effectiveness. Jossey-Bass.

Argyris, C., \& Schon, D. A. (1997). Organizational learning: A theory of action perspective. Reis.

Bandura, A. (1977). Self-efficacy: toward a unifying theory of behavioral change. Psychological review, 84(2), p. 191.

Bandura, A. (1982). Self-efficacy mechanism in human agency. American psychologist, 37(2), p. 122.

Bandura, A., Freeman, W. H., \& Lightsey, R. (1997). Self-efficacy: The exercise of control. Journal of cognitive psychotherapy, 13(2), pp. 158-166.

Barr, M. (2019). Graduate skills and game-based learning. Digital education and learning. Palgrave Macmillan, Cham.

Blanco-Herrera, J. A., Gentile D. A., \& Rokkum, J. N. (2019). Video games can increase creativity, but with caveats, Creativity Research Journal, 3(20), pp. 119-131.

Bowers, A. J. \& Berland, M. (2013). Does recreational computer use affect high school achievement? Educational technology research and development, 61(1), pp. 51-69.

Carless, S. (2011). Road to the IGF: Alexander Bruce's Hazard: The Journey of Life, Game Set Watch.

Chen, J. J. (2007). Flow in games (and everything else). Communications of the ACM, 50(4), pp. 31-34.

Chiu S.-I., Lee J.-Z. \& Huang D.-H. (2004). Video game addiction in children and teenagers in Taiwan. Cyberpsychology \& behavior, 7(5), pp.571-581. 


\section{Issues in Information Systems}

Volume 22, Issue 2, pp. 1-20, 2021

Chuang, T.-Y., \& Chen, W.-F. (2007). Effect of computer-based video games on children: An experimental study. 2007 First IEEE International Workshop on Digital Game and Intelligent Toy Enhanced Learning (DIGITEL'07).

Cooper, S., Khatib, F., Treuille, A., Barbero, J., Lee, J., Beenen, M., Leaver-Fay, A., Baker, D., \& Popović, Z. (2010). Predicting protein structures with a multiplayer online game. Nature, 466(7307), p. 756.

Couger, J. D., Higgins, L. F., \& McIntyre, S. C. (1993). (Un) structured creativity in information systems organizations, MIS Quarterly, (17)4, pp. 375-397.

Crookall, D. (2010). Serious games, debriefing, and simulation/gaming as a discipline. Simulation \& gaming, 41(6), pp. 898-920.

Csikszentmihalyi, M. (1988). The flow experience and its significance for human psychology. Cambridge University Press.

Dreyfus, S. E., \& Dreyfus, H. L. (1980). A five-stage model of the mental activities involved in directed skill acquisition (No. ORC-80-2). California Univ Berkeley Operations Research Center.

Egenfeldt-Nielsen, S. (2006). Overview of research on the educational use of video games. Nordic journal of digital literacy, 1(03), pp. 184-214.

Ferguson, C. J. (2007) The good, the bad and the ugly: A meta-analytic review of positive and negative effects of violent video games. Psychiatric quarterly, 78(4), pp. 309-316.

Gallagher, D., \& Grimm, L. R., (2018). Making an impact: The effects of game making on creativity and spatial processing. Thinking skills and creativity, 28, pp.138-149.

Gampell, A., Gaillard, J. C., Parsons, M., \& Le Dé, L. (2020). 'Serious' disaster video games: An innovative approach to teaching and learning about disasters and disaster risk reduction. Journal of geography, 119(5), pp. 159-170.

Gee, J. P. (2003). What video games have to teach us about learning and literacy. Computers in entertainment (CIE), 1(1), p. 20.

Gee, J. P. (2005). Learning by design: Good video games as learning machines. E-learning, 2(1), pp. 5-16.

Kao, G. Y.-M., Chiang, C.-H., \& Sun, C.-T. (2017). Customizing scaffolds for game-based learning in physics: Impacts on knowledge acquisition and game design creativity. Computers \& education, 113, pp. 294-312.

Granic, I., Lobel, A., \& Engels, R. C. J. (2014). American psychologist. The benefits of playing video games. 69(1), p. 66.

Green, G., \& Kaufman, J. C. (2015). Video games and creativity. Academic Press.

Greitemeyer, T., \& Osswald, S. (2010). Effects of prosocial video games on prosocial behavior. Journal of personality and social psychology, 98(2), p. 211. 


\section{Issues in Information Systems}

Volume 22, Issue 2, pp. 1-20, 2021

Hall, A. K., Chavarria, E., Maneeratana, V., Chaney, B. H., \& Bernhardt, J. M. (2012) Health benefits of digital videogames for older adults: a systematic review of the literature. Games for health: research, development, and clinical applications, 1(6), pp. 402-410.

Hamari, J., Shernoff, D. J., Rowe, E., Coller, B., Asbell-Clarke, J., \& Edwards, T. (2016) Challenging games help students learn: An empirical study on engagement, flow and immersion in game-based learning. Computers in human behavior, 54, pp. 170-179.

Hoeft, F., Watson, C. L., Kesler, S. R., Bettinger, K. E., \& Reiss, A. L. (2008). Gender differences in the mesocorticolimbic system during computer game-play. Journal of psychiatric research, 42(4), pp. $\underline{253-258 .}$

Hutton, E., \& Sundar, S. S. (2010). Can video games enhance creativity? Effects of emotion generated by Dance Revolution. Creativity research journal, 22(3), pp. 294-303.

Ibáñez, M-B., Di-Serio, A. \& Delgado-Kloos, C. (2014). Gamification for engaging computer science students in learning activities: A case study. IEEE Transactions on learning technologies, 7(3), pp. $\underline{291-301 .}$

Kolek, L., Šisler, V., Brom, C. (2019). Video games and attitude change-can we reliably measure this? The challenges of empirical study design. In: Gentile M., Allegra M., Söbke H. (eds) Games and Learning Alliance. GALA 2018. Lecture Notes in Computer Science, 11385. Springer, Cham.

Koufaris, M. (2002). Applying the technology acceptance model and flow theory to online consumer behavior. Information systems research, 13(2), pp. 205-223.

Marcos, J. (2005). Logics of essence and accident. Bulletin of the section of logic, 34(1), pp. 43-56.

Mathiak, K., \& Weber, R. (2006). Toward brain correlates of natural behavior: fMRI during violent video games. Human Brain Mapping, 27(12), pp. 948-956.

McClernon, C. K. (2009). Stress effects on transfer from virtual environment flight training to stressful flight environments. NAVAL POSTGRADUATE SCHOOL MONTEREY CA.

McGonigal, J. (2011). Reality is broken: Why games make us better and how they can change the world: Penguin.

Nelson, R. A., \& Strachan, I. (2009). Action and puzzle video games prime different speed/accuracy tradeoffs. Perception, 38(11), pp. 1678-1687.

Payne, K. C., J Keith, M., Babb, J., \& N Spruill, A. (2018). Development and validation of the information systems creative self-efficacy scale. In Proceedings of the 51st Hawaii International Conference on System Sciences (HICSS 2018).

Polanyi, M. (2009). The tacit dimension. University of Chicago press.

Powers, K. L., Brooks, P. J., Aldrich, N. J., Palladino, M. A., \& Alfieri, L. (2013) Effects of video-game play on information processing: a meta-analytic investigation. Psychonomic bulletin \& review, 20(6), pp. 1055-1079. 


\section{Issues in Information Systems}

Volume 22, Issue 2, pp. 1-20, 2021

Quick, J. M., \& Atkinson, R. K. (2011, June). A data-driven taxonomy of undergraduate student videogame enjoyment. In Proceedings of the 7th international conference on Games + Learning + Society Conference (pp. 185-190). ETC Press.

Ravaja, N., Saari, T., Salminen, M., Laarni, J., \& Kallinen, K. (2006). Phasic emotional reactions to video game events: A psychophysiological investigation. Media psychology, 8(4), pp. 343-367.

Rein, M., \& Schon, D. A. (1995). Frame reflection: Toward the resolution of intractable policy controversies. Basic Books.

Rüth, M., \& Kaspar, K. (2020). Commercial video games in school teaching: Two mixed methods case studies on students' reflection processes. Frontiers in psychology, 11, p. 3802.

Ryan, R. M., Rigby, C. S., \& Przybylski, A. (2006). The motivational pull of video games: A selfdetermination theory approach. Motivation and emotion, 30(4), pp. 344-360.

Schell, J. (2014). The art of game design: A book of lenses. AK Peters/CRC Press.

Schon, D. A. (1971). Beyond the stable state: Public and private learning in a changing society. Maurice Temple Smith Limited.

Schon, D. A. (1983). The reflective practitioner: How professionals think in action. Basic Books.

Schon, D. A. (1987). Educating the reflective practitioner: Toward a new design for teaching and learning in the professions. Jossey-Bass.

Schon, D. A. (1993). Generative metaphor: A perspective on problem-setting in social policy. Cambridge University Press.

Schon, D. A., \& Argyris, C. (1996). Organizational learning II: Theory, method and practice. Massachusetts: Addison-Wesley Publishing Company.

Shankar, V., \& Bayus, B. L. (2003). Network effects and competition: An empirical analysis of the home video game industry. Strategic management journal, 24(4), pp. 375-384.

Smith, S.L. (2006). Perps, pimps, and provocative clothing: Examining negative content patterns in video games. In P. Vorderer \& J. Bryant (Eds.), Playing video games: Motives, responses, and consequences (p. 57-75). Lawrence Eribaum Associates Publishers.

Squire, K. D. (2008). Video games and education: Designing learning systems for an interactive age. Journal of educational technology, 48(2), pp. 17-26.

Subhash, S., \& Cudney, E. A. (2018). Gamified learning in higher education: A systematic review of the literature, Computers in human behavior, 87, pp. 192-206.

Tekinbaş, K.S., \& Zimmerman, E. (2003). Rules of play: Game design fundamentals. Cambridge, Mass: MIT Press. 


\section{Issues in Information Systems}

Volume 22, Issue 2, pp. 1-20, 2021

Tierney, P., \& Farmer, S. M. (2002). Creative self-efficacy: Its potential antecedents and relationship creative performance. Academy of management journal, (45)6, pp. 1137-1148.

Tiwana, A., \& Mclean, E. R. (2005). Expertise integration and creativity in information systems development. Journal of management information systems, (22)1, pp. 13-43.

Totilo, S. (2011). 8 1/2 Minutes of Antichamber My Favorite Game of PAZ 2011. It's 'First-Person Escher.,' Kotaku.com.

Treiblmaier, H., Putz, L. M., \& Lowry, P. B. (2018). Research commentary: setting a definition, context, and theory-based research agenda for the Gamification of non-gaming applications. AIS Transactions on human-computer interaction, 10(3), 129-163.

Trope, Y., \& Liberman, N. (2010). Construal-level theory of psychological distance. Psychological review, $117(2)$, p. 440.

Zackariasson, P., Styhre, A., \& Wilson, T. L. (2006). Phronesis and creativity: Knowledge work in video game development. Creativity and innovation management, 15(4), pp. 419-429. 